\title{
V. CONCLUSIONS
}

The results of this investigation suggest that upon rapid cooling uranium undergoes a martensitic $\beta \longrightarrow \alpha$ transformation, thereby adding weight to other documented evidence. Many of the conflicting arguments against such a mechanism stem from assuming a shear hypothesis for martensitic transformation which permits no depression of the transformation point by increased cooling rates, and from the nature of the transformation during slow cooling where diffusion would be expected to predominate.

Further difficulty in realizing the true nature of the $\beta \longrightarrow \alpha$ transformation is the complexity of grain formation. Grain growth during rapid cooling might occur by a combination of diffusion and nondiffusion mechanisms to satisfy valence bonding and close packing requirements of the atoms simultaneously. It has been suggested that sub-graining prominent in $\alpha$ grains results from combined polygonization and nuclei rotation. As a result, uranium cooled at moderate rates through the transformation point should exhibit less distortion and more sub-graining due to polygonization than uranium cooled at much faster rates.

From the data presented in this report, a time-temperaturetransformation diagram for uranium may be sketched as shown in Figure 10. The precise location of the boundaries shown await more extensive investigation.

It is most significant that a wide range of structures with varying grain size, symmetry, and deformation can be obtained by controlling the cooling rate through the $\beta \longrightarrow \alpha$ transformation. Further knowledge of the effect of these variants on the mechanical properties of uranium are required before optimum heat treatments can be specified. 
A MARTENSITIC REACTION FOR URANIUM

By

A. L. Bement and W. P. Wallace

Fuels Development

Reactor and Fuels Research and Development Operation

June 25, 1957

\section{HANFORD ATOMIC PRODUCTS OPERATION RICHLAND, WASHINGTON}

Work performed under Contract No. W-31-109-Eng-52 between the Atomic Energy Commission and General Electric Company

Printed by/for the U. S. Atomic Energy Commission

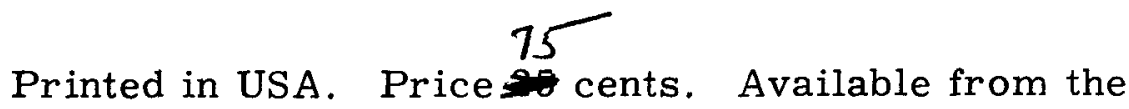

Office of Technical Services

U.S. Department of Commerce

Washington 25, D. C. 


\section{DISCLAIMER}

This report was prepared as an account of work sponsored by an agency of the United States Government. Neither the United States Government nor any agency Thereof, nor any of their employees, makes any warranty, express or implied, or assumes any legal liability or responsibility for the accuracy, completeness, or usefulness of any information, apparatus, product, or process disclosed, or represents that its use would not infringe privately owned rights. Reference herein to any specific commercial product, process, or service by trade name, trademark, manufacturer, or otherwise does not necessarily constitute or imply its endorsement, recommendation, or favoring by the United States Government or any agency thereof. The views and opinions of authors expressed herein do not necessarily state or reflect those of the United States Government or any agency thereof. 


\section{DISCLAIMER}

Portions of this document may be illegible in electronic image products. Images are produced from the best available original document. 
INTERNAL DISTRIBUTION

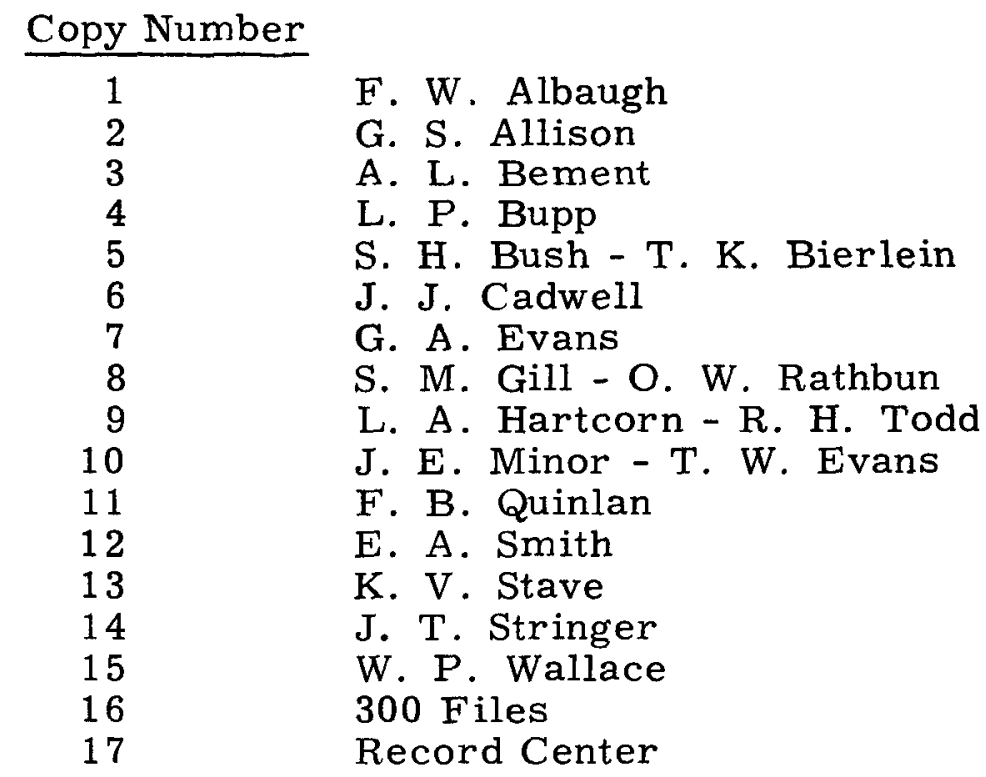

\section{EXTERNAL DISTRIBUTION}

Copy Number

$18-19$
20
$21-30$
$31-35$
36
37
$38-40$
$41-42$
$43-44$
$45-48$
49
$50-51$
52
53
54
55
56
$57-58$
59
60

Aberdeen Proving Ground

Alco Products, Inc.

Argonne National Laboratory

Armed Services Technical Information Agency, Dayton Atlantic Fleet

Atomic Energy Commission, Patent Branch

Atomic Energy Commission, Technical Library

Atomics International

Battelle Memorial Institute

Bettis Plant

Boeing Airplane Company

Brookhaven National Laboratory

Brush Beryllium Company

Bureau of Ships (Code 590)

Chicago Patent Group

Columbia University (Dr. Hassialis)

Combustion Engineering, Inc.

Consolidated Vultee Aircraft Corporation

Convair-General Dynamics

Defence Research Member 
EXTERNAL DISTRIBUTION (Contd.)

Copy Number

\begin{tabular}{|c|c|c|}
\hline 61 & & Department of Food Technology (MIT) \\
\hline 62 & & Department of Navy (Code 422 ) \\
\hline 63 & -64 & Department of the Army, G-2 \\
\hline 65 & -66 & Division of Raw Materials, Denver \\
\hline 67 & & Dow Chemical Company, Pittsburg \\
\hline 68 & & Dow Chemical Company (Rocky Flats) \\
\hline 69 & -72 & Du Pont de Nemours and Company, Aiken \\
\hline 73 & & Du Pont de Nemours and Company, Wilmington \\
\hline 74 & & Frankford Arsenal \\
\hline 75 & -76 & General Electric Company (ANPP) \\
\hline 77 & & General Nuclear Engineering Corporation \\
\hline 78 & -79 & Goodyear Atomic Corporation \\
\hline 80 & -81 & Iowa State College \\
\hline 82 & & Kirtland Air Force Base \\
\hline 83 & -85 & Knolls Atomic Power Laboratory \\
\hline 86 & -87 & Lockheed Aircraft Corporation (Bauer) \\
\hline 88 & -90 & Los Alamos Scientific Laboratory \\
\hline 91 & -92 & Mallinckrodt Chemical Works \\
\hline 93 & & Mound Laboratory \\
\hline 94 & & National Advisory Committee for Aeronautics, Cleveland \\
\hline 95 & -96 & National Bureau of Standards, Atomic Energy Project \\
\hline $\begin{array}{l}97 \\
98\end{array}$ & & National Bureau of Standards (Library) \\
\hline $\begin{array}{l}98 \\
99\end{array}$ & & National Lead Company, Inc., Winchester \\
\hline 99 & -100 & National Lead Company of Ohio \\
\hline 101 & -103 & Naval Research Laboratory \\
\hline 104 & & New Brunswick Area Office \\
\hline 105 & -106 & New York Operations Office \\
\hline 107 & & Nuclear Development Corporation of America \\
\hline 108 & & Nuclear Metals, Inc. \\
\hline 109 & & Oak Ridge Institute of Nuclear Studies \\
\hline 110 & -115 & Oak Ridge National Laboratory \\
\hline 116 & -117 & Office of Naval Research \\
\hline 118 & -121 & Phillips Petroleum Company \\
\hline 122 & & RAND Corporation \\
\hline 123 & -124 & Sandia Corporation \\
\hline 125 & & Signal Corps Center \\
\hline 126 & & Sylvania Electric Products, Inc. \\
\hline 127 & & Union Carbide Nuclear Company (C-31 Plant) \\
\hline 128 & & Union Carbide Nuclear Company (K-25 Plant) \\
\hline 130 & & United Aircraft Corporation \\
\hline 133 & & U. S. Geological Survey, Denver \\
\hline
\end{tabular}


EXTERNAL DISTRIBUTION (Contd.)

Copy Number

134

135

136

137

$138-139$

$140-141$

142

143

144

$145-146$

$147-446$

$447-546$
U. S. Geological Survey, Menlo Park

U. S. Geological Survey, Washington

U. S. Naval Postgraduate School

U. S. Patent Office

University of California Radiation Laboratory, Berkeley

University of California Radiation Laboratory, Livermore Vitro Engineering Division

Watertown Arsenal

Weil, Dr. George L.

Westinghouse Electric Corporation

Technical Information Service Extension, Oak Ridge

Office of Technical Services, Washington 


\section{A MARTENSITIC REACTON FOR URANIUM}

\section{INTRODUCTION}

A series of isothermal transformation studies has been initiated to gain new knowledge concerning the heat treatment and resulting microstructures of uranium. Of particular interest are the variables encountered in heat treating thin sections such as wafers and tubes that make up segmented fuel elements. For the most part, however, the resulting data will also be applicable to solid cores. The knowledge obtained will be beneficial in improving not only fabrication but also the reactor performance of uranium fuel elements.

When high-purity uranium is cooled through the $\beta \rightarrow \alpha$ transformation the appearance of the resulting alpha grain structure depends a great deal upon the rate of cooling. ${ }^{(1)}$ For fast cooling rates, i.e., those obtained by water quenching, the resulting structure is highly twinned, grain boundaries are jagged, and sub-grains are numerous. On the other hand, slower cooling rates resulting from air or furnace cooling yield larger alpha grains with relatively straight grain boundaries, fewer twins, and fewer discernible sub-grains. ${ }^{(2)}$

There is increasing evidence that the $\beta \rightarrow \alpha$ transformation is (partially at least) martensitic in nature and obeys nucleation and growth kinetics. For example, Duwez ${ }^{(3)}$ measured transformation temperatures for different cooling rates and found that the $\beta \rightarrow \alpha$ transformation could be depressed below $400 \mathrm{C}$ at cooling rates of the order of $8000 \mathrm{C} / \mathrm{sec}$. However, he was not able to depress the transformation of pure uranium to room temperature. The first observation is contrary to the shear hypothesis for martensitic transformation which states that transformation occurs very rapidly and is a function only of temperature and not of cooling rate. ${ }^{(4)}$ The second observation implies a martensitic transformation in that the $\beta \rightarrow \alpha$ transformation cannot be depressed to room temperature, 
but can be depressed to temperature where rapid recrystallization (a diffusion process) does not occur. The depression of a martensitic reaction can be explained by a nucleation and growth hypothesis which has been advanced and widely endorsed.

Furthermore, White ${ }^{(6)}$ observed two transformations in cooling dilute U-Cr alloys from the $\beta$ phase. He speculated that the one at higher temperatures is diffusion controlled and the one at lower temperatures diffusionless (martensitic). Extrapolating his " $\mathrm{C}$ " curves to zero chromium content, one would conclude that pure uranium transforms by this lower mechanism alone. Holden ${ }^{(7)}$ and Butcher ${ }^{(8)}$ independently observed that the texture of $\alpha$ phase transformed from $\beta$ single crystals was very similar to that of dilute $\mathrm{U}-\mathrm{Cr}$ alloys martensitically transformed from $\beta$ single crystals.

A basic characteristic of martensitic transformations is the maintenance of lattice coherency during transformation. ${ }^{(5)}$ In other words, neighboring atoms in one phase remain neighbors in the subsequent phase. The grains of uranium quenched from the $\beta$ phase exhibit plastic strain which may accompany coherency requirements for a boundary expanding martensitically. The more uniform grain appearance of slowly cooled uranium indicates that diffusion processes are operating; however, the ever-present twinning reveals that non-annealed cooling strains also occur. Although the $\beta \rightarrow \alpha$ transformation in uranium may be a compromise between non-diffusion and diffusion processes, the predominance of either process is a function of the cooling rate through the transformation point which, therefore, determines the final grain size and appearance.

The proposition was made that the amount of strain and the grain size induced by $\beta \rightarrow \alpha$ transformation at various cooling rates should be observable by carefully controlled hardness measurements. This report presents and interprets the data obtained by this method. 


\section{SUMMARY}

Hardness measurements of specimens quenched from the $\beta \rightarrow \alpha$ phase at different cooling rates support the proposed martensitic $\beta \rightarrow \alpha$ transformation for uranium. Specimens held in 635 and $600 \mathrm{C}$ isothermal baths prior to subsequent quenching to $-5 \mathrm{C}$ require more than 10 and two seconds respectively before diffusion mechanisms for $\beta \rightarrow \alpha$ transformation commence. Once started, about 500 seconds are required to complete transformation by diffusion at these temperatures. Specimens quenched prior to this hold time transform in part martensitically. Relationships are calculated for hardness as a function of grain size and cooling rate, and for grain size as a function of cooling rate. Metallographic examination confirms the hardness trends and reveals that widely varied grain structures can be produced by controlled cooling from the $\beta$ phase. Finally, a schematic time-temperature-transformation curve is sketched from the hardness data obtained.

\section{PROCEDURE}

Uranium specimens $3 / 4$-inch square and $1 / 4$-inch thick were machined from 5/16-inch, as-rolled strip. A small hole was drilled near one side so that the specimen could be suspended in the heat treating baths with "ni-chrome"wire. The specimens were held in the $\beta$ range for two minutes at $730 \mathrm{C}$, were quickly transferred to an isothermal bath for different times, and were finally either air cooled or quenched in refrigerated brine. Transfer between baths was within two seconds, and the brine was maintained at $-5 \mathrm{C}$ with dry ice. Houghton "liquid-heat 300 " was used for the $\beta$ heat treating bath and for isothermal baths at 635 and $600 \mathrm{C}$. Lead was used for baths at 500 and $400 \mathrm{C}$.

Following heat treatment, two parallel rectangular faces of the specimens were ground to remove a slight oxide film and produce smooth, plane surfaces. The faces selected were those in the rolling direction and normal to the rolling plane. The specimens were ground through 80 and 
240 -grit belts on a wet-belt grinder. In addition, they were given a light grind through 320-grit paper using paraffin-kerosene lubricant to remove any worked surface. Hardness was measured with a Rockwell tester, using the "A" scale.

To photograph grain structures, the side opposite that used for hardness measurement was further ground, polished, and etched by standard techniques. Photomicrographs at $100 \mathrm{X}$ magnifications were taken of the geometrical center of the face.

IV. RESULTS AND DISCUSSION

Mean hardness values are listed in Table I and plotted in Figures $1,2,3$, and 4 . In general, the variations in hardness were $+1,-1.5$ points above $R_{A} 57$ and about $+1.5,-2.5$ points below $R_{A} 57$. Grain sizes of the specimens are also listed in Table I. Major impurities in the uranium used are listed in the Appendix.

Figures 1, 2, 3, and 4 are plots of the hardness of brine-quenched and air-cooled specimens as a function of time at isothermal, holding-bath temperatures. The characteristics of these plots may be summarized as follows:

1. For holding-bath temperatures near the equilibrium transformation point (about $665 \mathrm{C}$ ) the holding time required for isothermal transformation* to occur depends upon thermal hysteresis; that is, the time in which the cooling rate decreases to where transformation can occur at or above the holding temperature. ** This is

* Isothermal transformation as referred to in this report is that which occurs in the holding bath prior to subsequent cooling. Transformation at constant temperature is referred to as equilibrium transformation.

** It should be pointed out that the time delay for isothermal transformation is also a function of the initial $\beta$ heat treating bath temperature. As this temperature varies, the cooling rate past the recalescence point (and subsequently, thermal hysteresis) varies.(9) This variance will increase or decrease depending upon the difference in temperature between the equilibrium transformation point and the isothermal bath. 


\section{TABLE I}

HARDNESS AND GRAIN SIZE OF SPECIMENS

\section{AFTER HEAT TREATMENT}

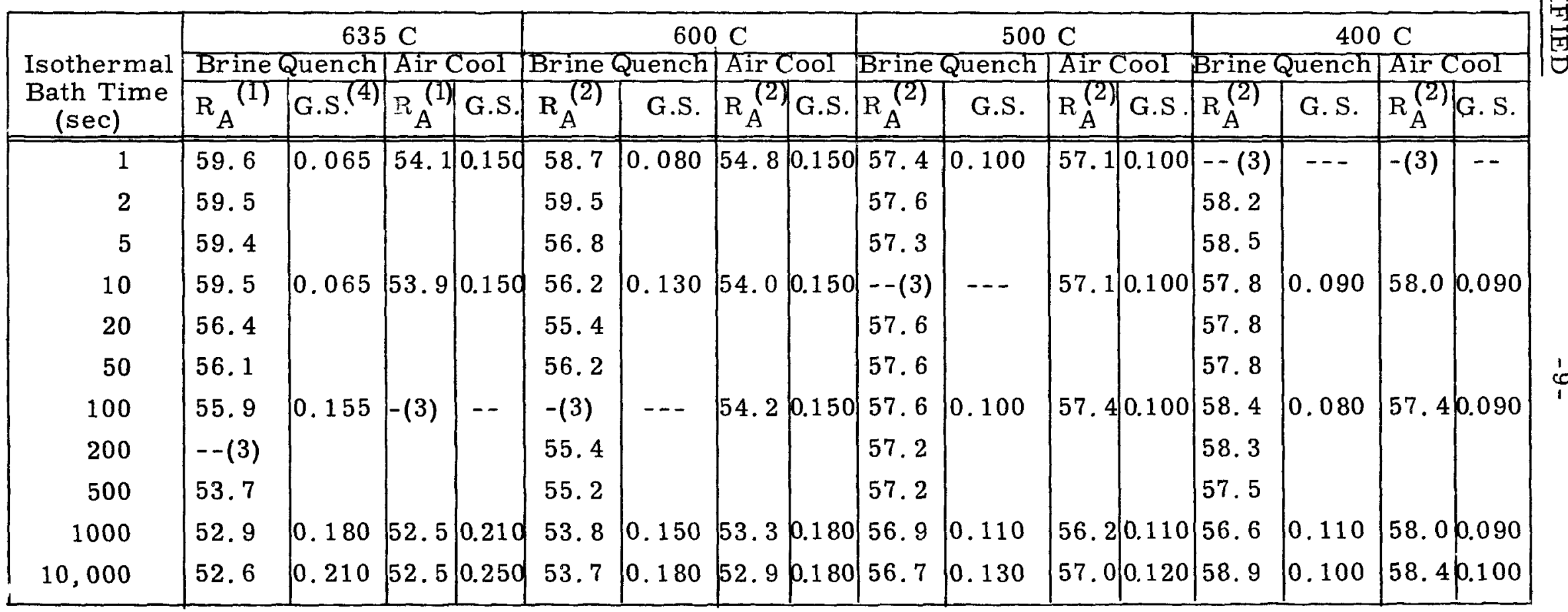

(1) Mean hardness value for 5 readings.

(2) Mean hardness value for 10 readings.

(3) Specimens either lost in holding bath or given excessive transfer time between baths.

(4) Grain size ( $\mathrm{mm})$ 
illustrated in Figures 1 and 2 where a sudden hardness drop occurs in the "brine-quenched" curves after 10 seconds and two seconds respectively. Prior to these times, $\beta \rightarrow \alpha$ transformation occurred during the brine quench.

2. At a bath temperature between 600 and $500 \mathrm{C}$, isothermal transformation begins to occur within one second. *

3. The hardness of both brine-quenched and air-cooled specimens remains fairly constant with holding time in the 500 and $400 \mathrm{C}$ baths. Furthermore, hardness increases and the air-cooled specimens approach the brine-quenched specimens in hardness as the holding-bath temperature decreases (cooling rate increases).

4. The rate of softening in the 635 and $600 \mathrm{C}$ baths becomes discontinuous in two locations on the "brine-quenched" curves forming "separated" plots from about 20 to 200 seconds and 5 to 500 seconds respectively. Furthermore, the hardness of the brinequenched specimens approaches nearly that of the air-cooled specimens with time. The small differences remaining are probably due to small differences in strains induced by cooling from the isothermal bath temperature to lower temperatures.

To determine the time required for transformation to commence for each holding-bath temperature, calculations were made using heat conduction theory and Duwez's ${ }^{(3)}$ transformation and cooling-rate data. The data from these calculations are listed in Table II. The calculated and observed times are in good agreement.

Returning to the "separated" portions of the hardness plots for the 635 and $600 \mathrm{C}$ baths, these apparently represent the time required to complete isothermal transformation by diffusion at temperatures near the

* This is not strictly true since transformation has undoubtedly occurred before the specimen has reached the temperature of the bath. 
equilibrium transformation point. A diffusion process is also indicated by the longer time required at $600 \mathrm{C}$ compared to $635 \mathrm{C}$ where diffusion is more rapid.

On the other hand, the differences in hardness between the "brine-quenched" and "air-cooled" curves for the same times indicate that subsequent hardening of the retained $\beta$ phase occurs upon rapid cooling from the holding temperature. Such hardening occurs by diffusionless transformation according to the time-length of the "separated" hardness plots.

\section{TABLE II}

CALCULATED AND OBSERVED TIMES FOR START OF ISOTHERMAL TRANSFORMATION

\begin{tabular}{ccccc}
\hline $\begin{array}{c}\text { Isothermal } \\
\text { Bath Temp } \\
\text { (C) }\end{array}$ & $\begin{array}{c}\mathrm{T}^{(1)} \\
\left(\mathrm{T}_{\mathrm{o}}-\mathrm{T}_{\mathrm{S}}\right) \\
(\mathrm{C} \mathrm{deg})\end{array}$ & $\begin{array}{c}\text { Cooling Rate Through } \\
\text { Transformation } \\
\text { (C deg/sec) }\end{array}$ & $\begin{array}{c}\text { Time } \\
\text { Calculated } \\
\text { (sec) }\end{array}$ & $\begin{array}{c}\text { Time } \\
\text { Observed } \\
\text { (sec) }\end{array}$ \\
\hline 635 & 95 & Approx. 0.5 & 8.0 & $10-20$ \\
600 & 130 & Approx. 10 & 2.2 & $2-5$ \\
500 & 230 & Approx. 90 & 0.5 & $0-1$ \\
400 & 330 & Approx. 400 & 0.2 & $0-1$ \\
\hline (1) $\mathrm{T}_{\mathrm{o}}$ is initial temperature (730 C), $\mathrm{T}_{\mathrm{S}}$ is holding-bath temperature.
\end{tabular}

Figure 5 is a plot of the hardness of the brine-quenched specimens at the first indication of transformation* for the corresponding holding temperatures as a function of the cooling rate through the transformation point (from Table II). A change of slope occurs at a cooling rate corresponding to about $570 \mathrm{C}$ and a hardness of about $56.8 \mathrm{R}_{\mathrm{A}}$. With cooling

* For holding-bath temperatures below $600 \mathrm{C}$ this corresponds to the hardness at 1 second holding time. For the 635 and $600 \mathrm{C}$ baths, the hardness values at 20 seconds and 5 seconds respectively are used. 
rates through the $\beta \rightarrow \alpha$ transformation greater than about $22 \mathrm{C} \mathrm{deg} / \mathrm{sec}$, the hardness increases at a more rapid rate than for cooling rates up to $22 \mathrm{C} \mathrm{deg} / \mathrm{sec}$.

Furthermore, Figure 6, a plot of hardness of the air-cooled specimens as a function of holding-bath temperature, shows a series of maximum slopes between 500 and $600 \mathrm{C}$. In other words, maximum increase in hardness occurs by quenching into an isothermal bath between 500 and $600 \mathrm{C}$ prior to air-cooling.

These two plots independently suggest that if a martensitic reaction is operative, it most probably occurs between 500 and $600 \mathrm{C}$ for the cooling rates investigated. Also, if such a reaction follows nucleation and growth kinetics, the exact point of transformation need not be the same for different cooling rates.

Because indentation hardness increases with increasing fineness of grains in polycrystalline metals, ${ }^{(10)}$ some relationship should exist between the hardness trends just discussed and the grain size and appearance of the specimens treated. Figure 7 illustrates such a relationship which is similar to the trend for other metals in the range of larger grains. ** It seems reasonable to expect an inflection among the points plotted for the brine-quenched specimens at about the same hardness as the inflection of Figure 5. As a first approximation straight lines are drawn through the cluster of points representing the brine-quenched specimens and within the range of values. The point of inflection is at 56. $7 \mathrm{R}_{\mathrm{A}}$ which is in excellent agreement with $56.8 \mathrm{R}_{\mathrm{A}}$ noted in Figure 5 . From these curves, the following relationships can be calculated:

** See, for example, "The Variation of Hardness with Grain Size for Copper", C. S. Barrett, Structure of Metals, p. 356, (1952). 


$$
\begin{aligned}
& \mathrm{H}_{\mathrm{A}}=55.3+0.5 \ln (\mathrm{R}) \quad(\mathrm{R}>20) \\
& \mathrm{H}_{\mathrm{A}}=55.4+0.021\left(\mathrm{D}^{-2}\right) \quad(\mathrm{D}<0.130) \\
& D=23.8[\ln (R)]^{-1 / 2} \quad(R>20)
\end{aligned}
$$

where

$$
\begin{aligned}
& \mathrm{H}_{A}=\text { hardness (Rockwell "A" Scale) } \\
& D=\text { grain diameter }(\mathrm{mm}) \\
& \mathrm{R}=\text { cooling rate }(\mathrm{C} \mathrm{deg} / \mathrm{sec})
\end{aligned}
$$

These functions are restricted to uranium of comparable purity to that listed in the Appendix and the cooling rate limitations noted. Furthermore, they are only approximations since a linear relationship between hardness and grain size is expected in a smaller grain size range than that obtainable by $\beta$ heat treating.

The microstructures of the specimens follow the trends of the hardness curves discussed. Photomicrographs are presented with corresponding hardness plots in Figure 8 and 9. The grain appearance of the $635 \mathrm{C}$ brine-quenched specimens up to 1000 seconds holding time are similar in that copious twinning and sub-graining are present; however, differences in grain size are apparent. Up to 10 seconds holding time the grain size is similar, but after 10 seconds the grains are noticeably larger, explaining the hardness drop at this point. Beyond 500 seconds, the grains are more regular in appearance, sub-grains are more subdued, and grain boundaries are more discernible. The air-cooled specimens are similar in appearance with only slight variation in grain size.

At the other extreme, both the air-cooled and brine-quenched specimens held at $400 \mathrm{C}$ are similar in grain size and appearance. This reveals that lead at $400 \mathrm{C}$ was an effective quenching medium and that diffusion was critically retarded at this temperature. The microstructures of specimens held at 600 and $500 \mathrm{C}$ fall between the two extremes. 


\section{CONCLUSIONS}

The results of this investigation suggest that upon rapid cooling uranium undergoes a martensitic $\beta \rightarrow \alpha$ transformation, thereby adding weight to other documented evidence. Many of the conflicting arguments against such a mechanism stem from assuming a shear hypothesis for martensitic transformation which permits no depression of the transformation which permits no depression of the transformation point by increased cooling rates, and from the nature of the transformation during slow cooling where diffusion would be expected to predominate.

Further difficulty in realizing the true nature of the $\beta \rightarrow \alpha$ transformation is the complexity of grain formation. Grain growth during rapid cooling might occur by a combination of diffusion and nondiffusion mechanisms to satisfy valence bonding and close packing requirements of the stoms simultaneously. It has been suggested that sub-graining prominent in $\alpha$ grains results from combined polygonization and nuclei rotation. ${ }^{(7)}$ As a result, uranium cooled at moderate rates through the transformation point should exhibit less distortion and more sub-graining due to polygonization than uranium cooled at much faster rates.

From the data presented in this report, a time-temperaturetransformation diagram for uranium may be sketched as shown in Figure 10. The precise location of the boundaries whown await more extensive investigation.

It is most significant that a wide range of structures with varying grain size, symmetry, and deformation can be obtained by controlling the cooling rate through the $\beta \leftrightarrow \alpha$ transformation. Further knowledge of the effect of these variants on the mechanical properties of uranium are required before optimum heat treatments can be specified. 


\section{REFERENCES}

1. Bement, A. L., An Investigation of the Properties of Uranium Related to the Quench after Beta Heat Treating, HW-33726, (1954).

2. Foote, F. G., Symposium on Nuclear Metallurgy, AIME, (1955).

3. Duwez, P., The Effect of the Rate of Cooling on the Allotropic Transformation Temperatures of Uranium, "AECD-3421, (1952).

4. Bowles, J. S. and Barrett, C. S., Progress in Metal Physics, $\underline{3}$ p. 2, (1952).

5. Turkalo, A., The Martensitic Reaction: Recent Russian Work (G. Kirdjumow), GERL-178, (1949).

6. White, D. W., Jr., J. Metals, 7, p. 1221, (1955).

7. Butcher, B. R., The Beta to Alpha Phase Change in Pure Uranium AERE M/R 1944, (1956).

8. Butcher, B. R. and Rowe, A. H., "Symposium on the Mechanism of Phase Transformation in Metals, "Institute of Metals, p. 229.

9. Ingersoll, L. R., Zobel, O. J., and Ingersoll, A. C. , Heat Conduction, p. 98, (1954).

10. Bassett, W. H. and Davis. C. H., Trans. AIME, 60, p. 428, (1919). 


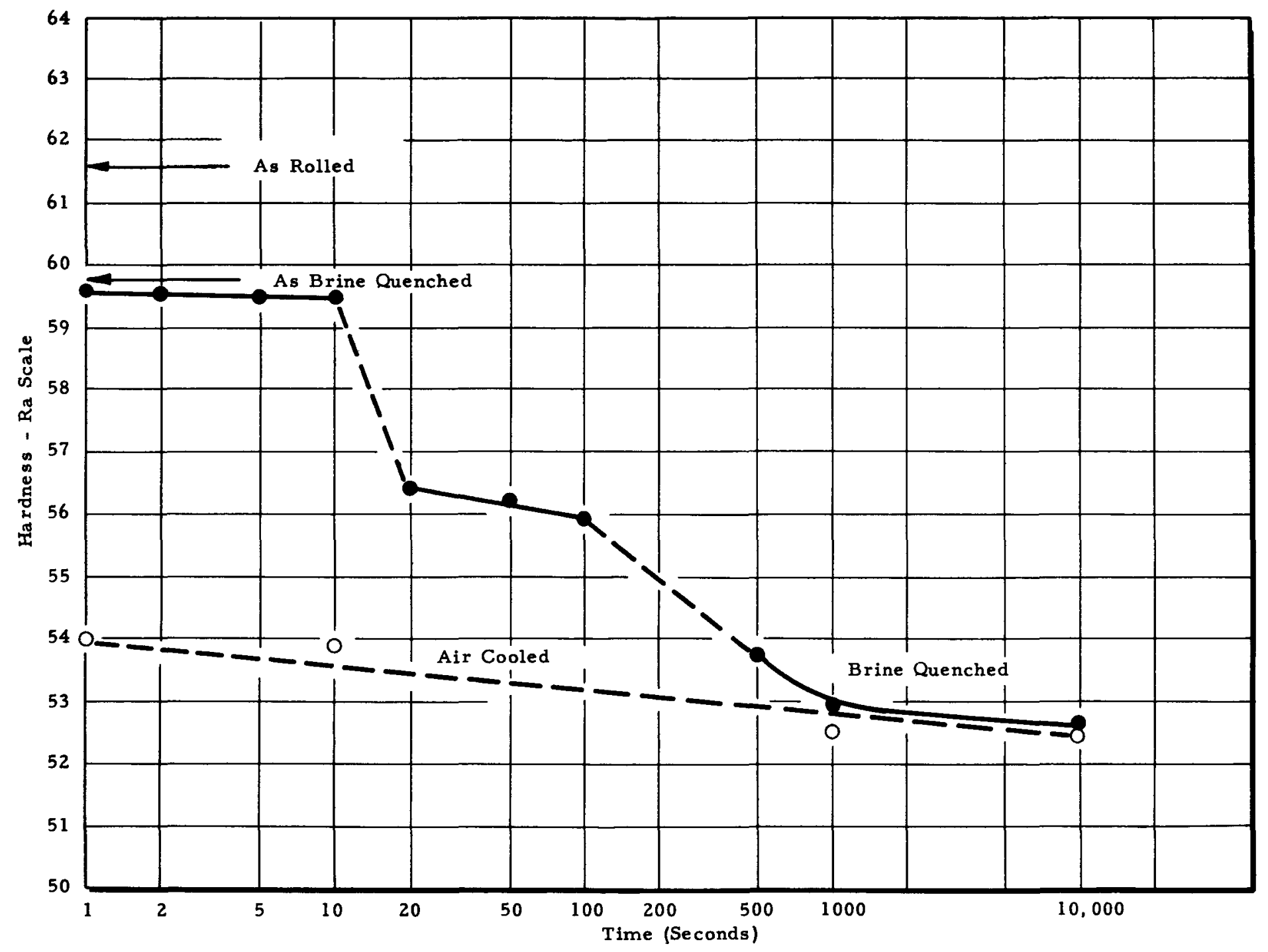

FIGURE 1

THE VARIATION OF HARDNESS WITH HOLDING TIME AT $635^{\circ} \mathrm{C}$ 


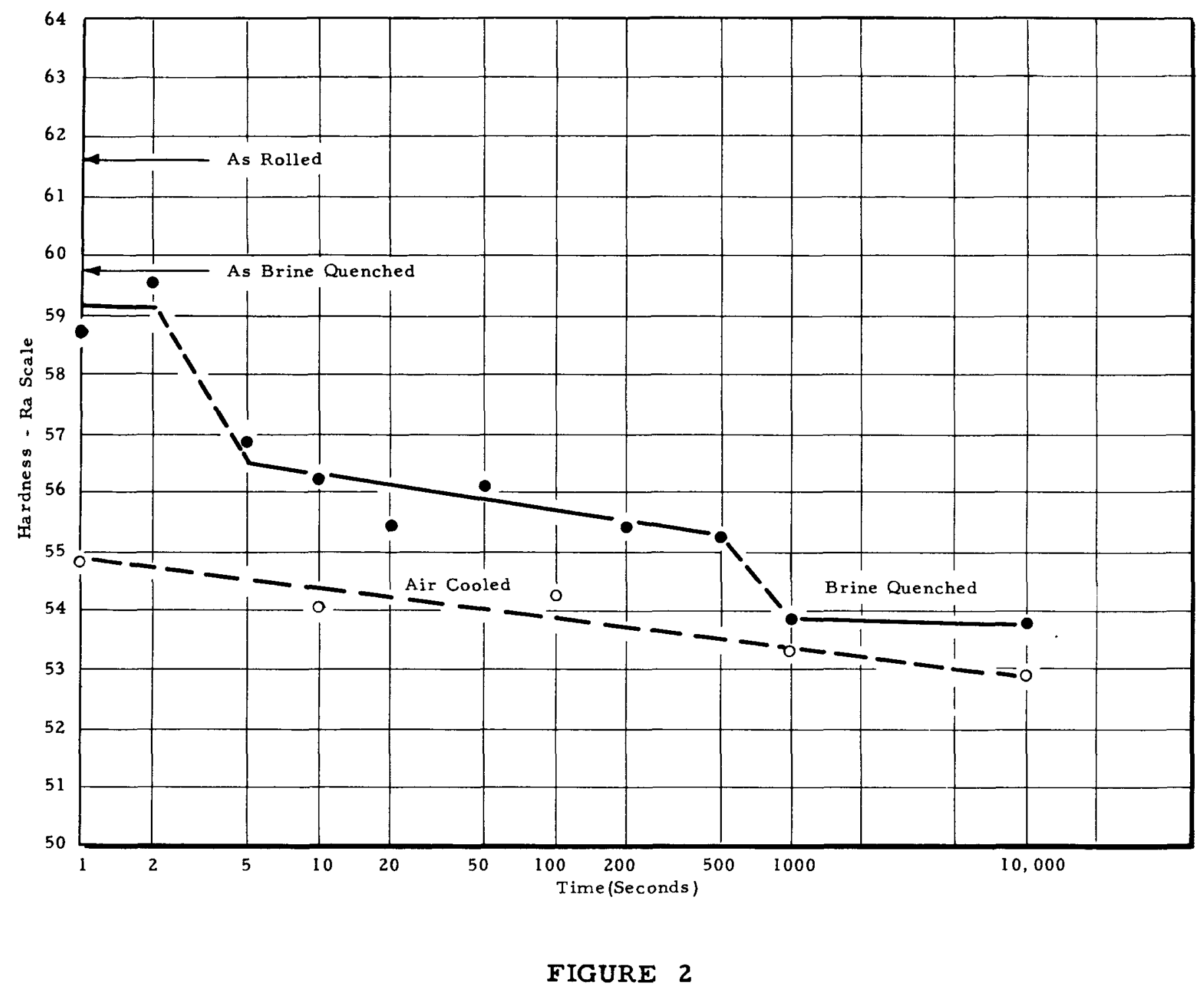

THE VARIATION OF HARDNESS WITH HOLDING TIME AT $600^{\circ} \mathrm{C}$ 


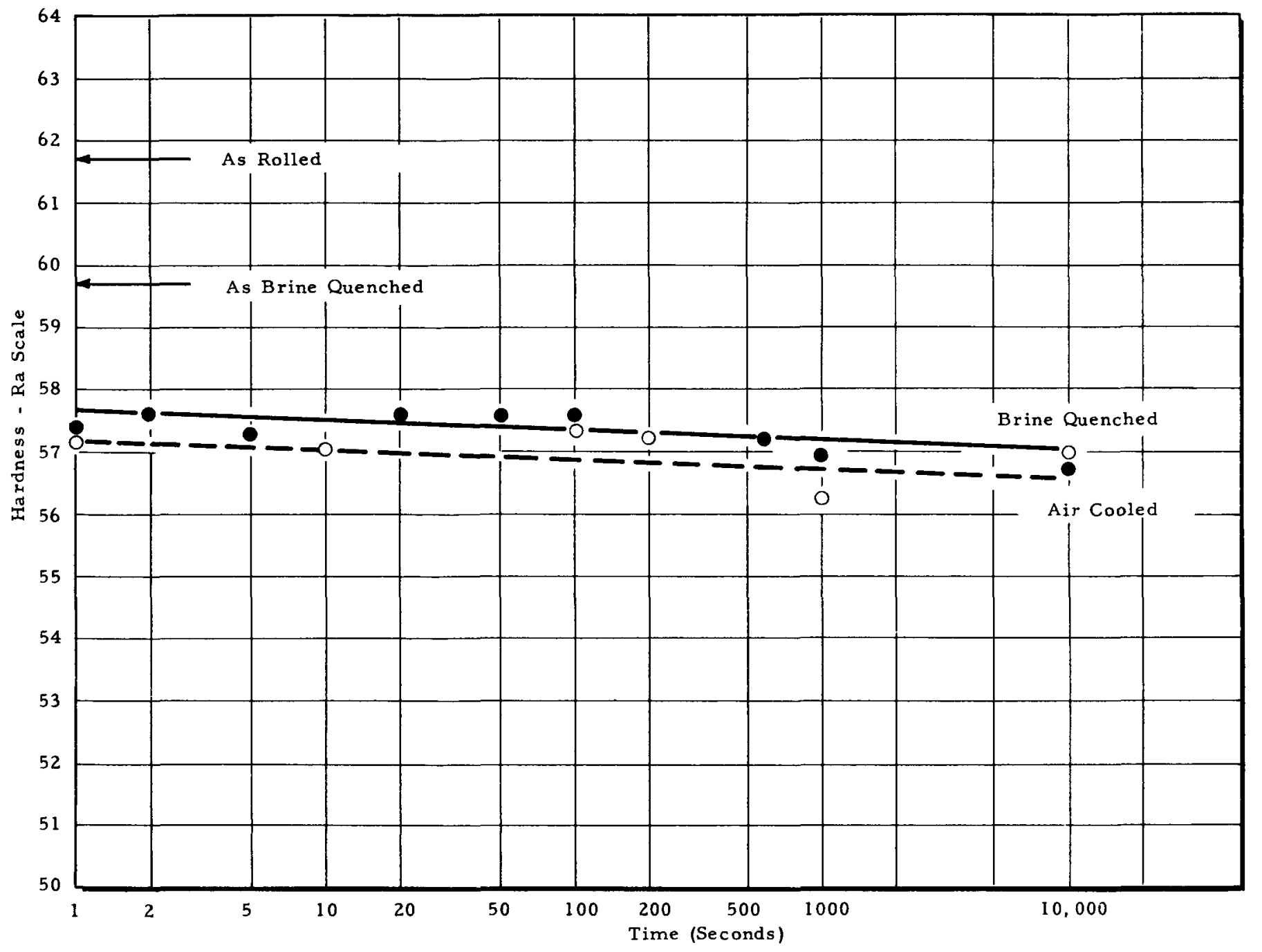

FIGURE 3 


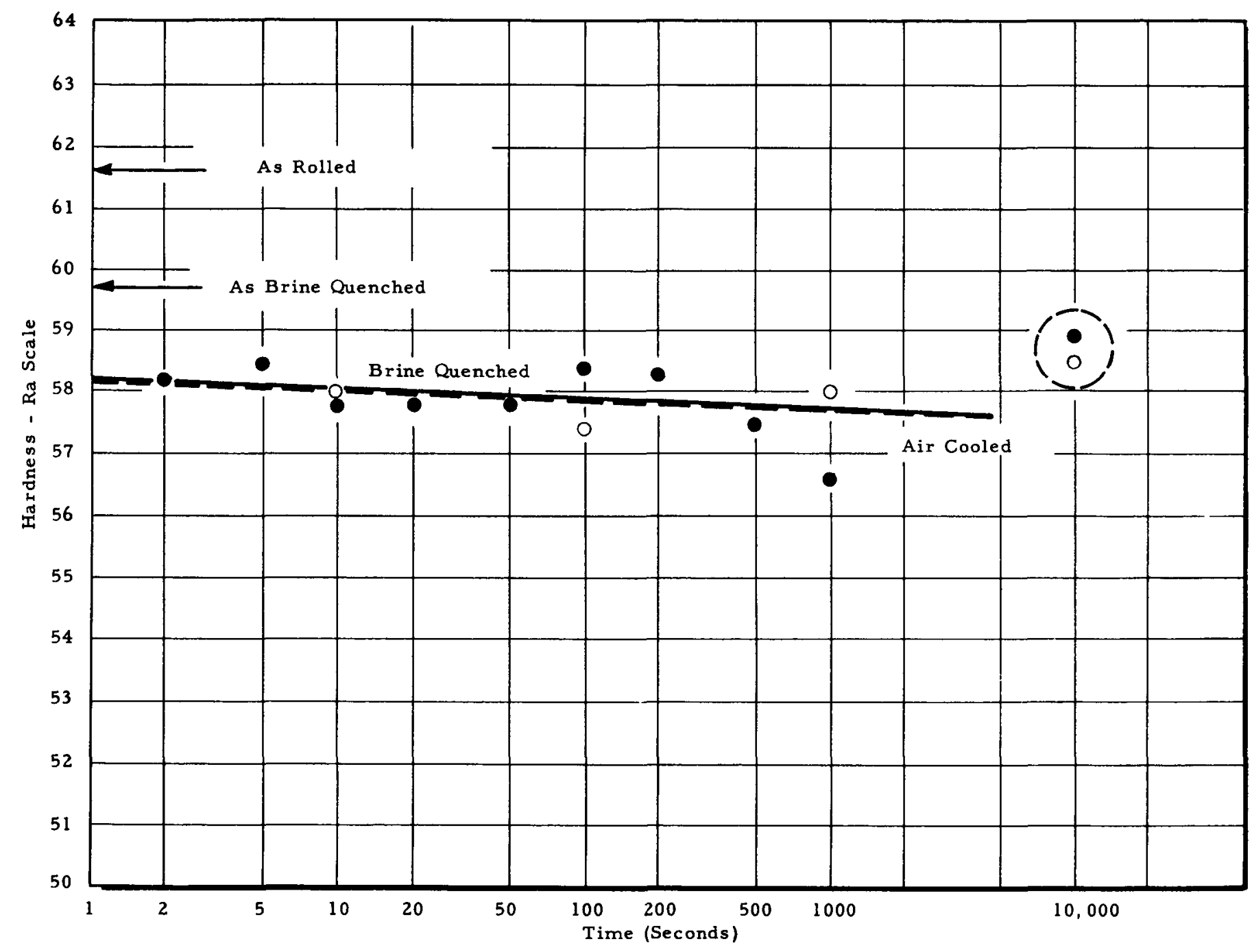

FIGURE 4

THE VARIATION OF HARDNESS WITH HOLDING TIME AT $400^{\circ} \mathrm{C}$ 


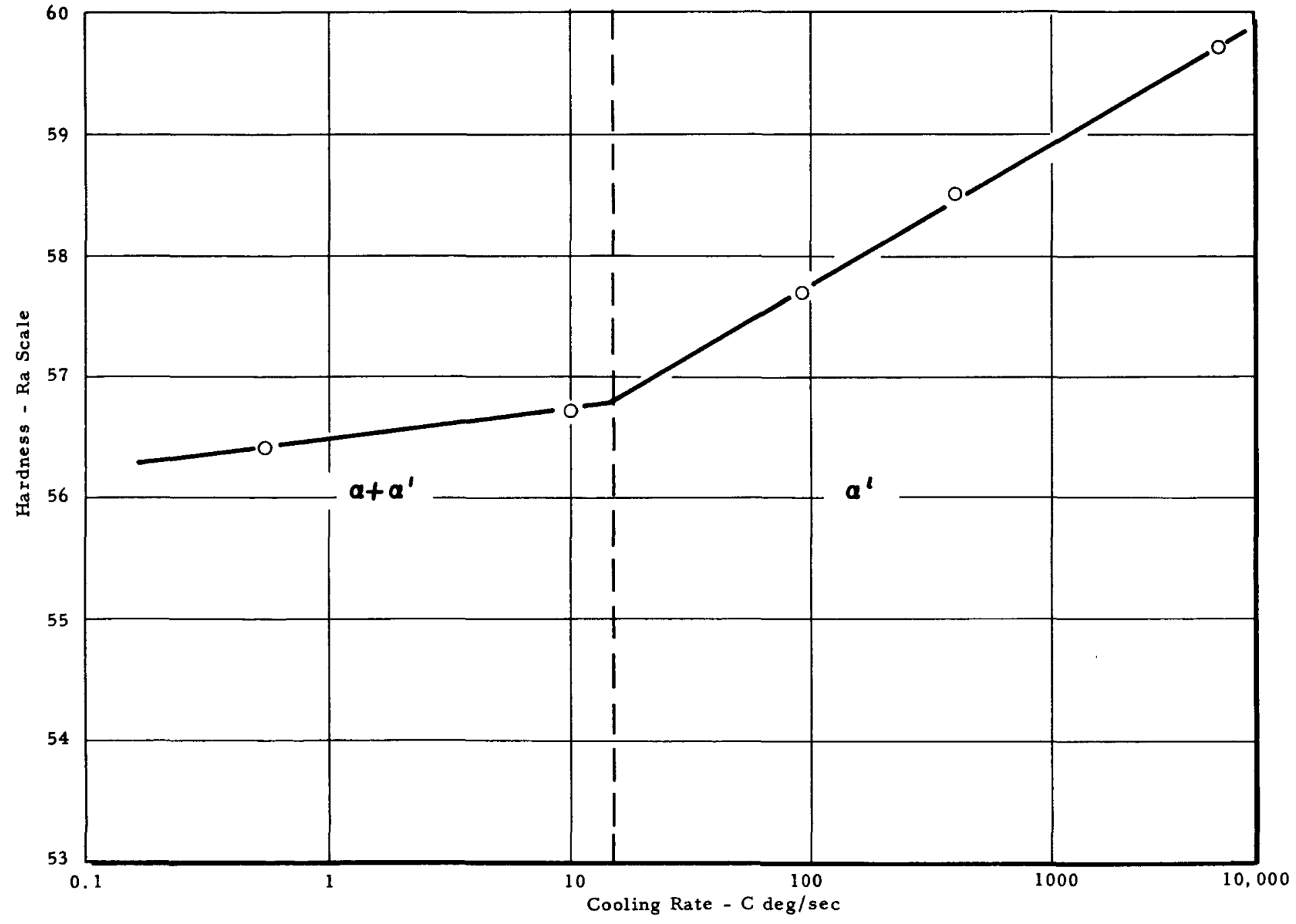

FIGURE 5

T HE VARIATION OF HARDNESS WITH COOLING RATE THROUGH TRANSFORMATION 


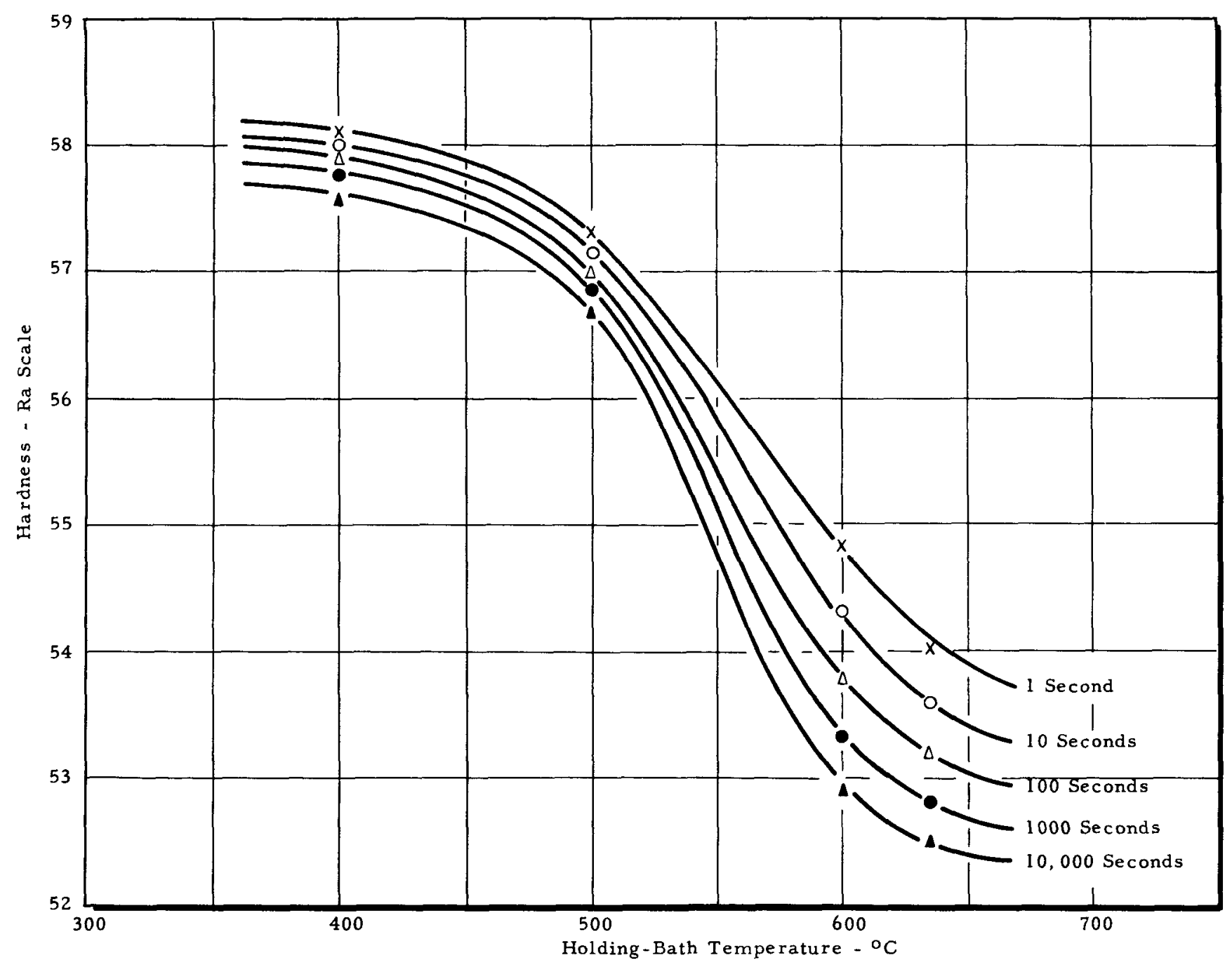

FIGURE 6

THE VARIATION OF HARDNESS WITH HOLDING BATH

TEMPERATURE - AIR COOLED SPECIMENS

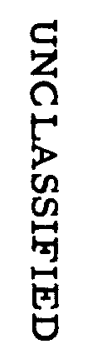




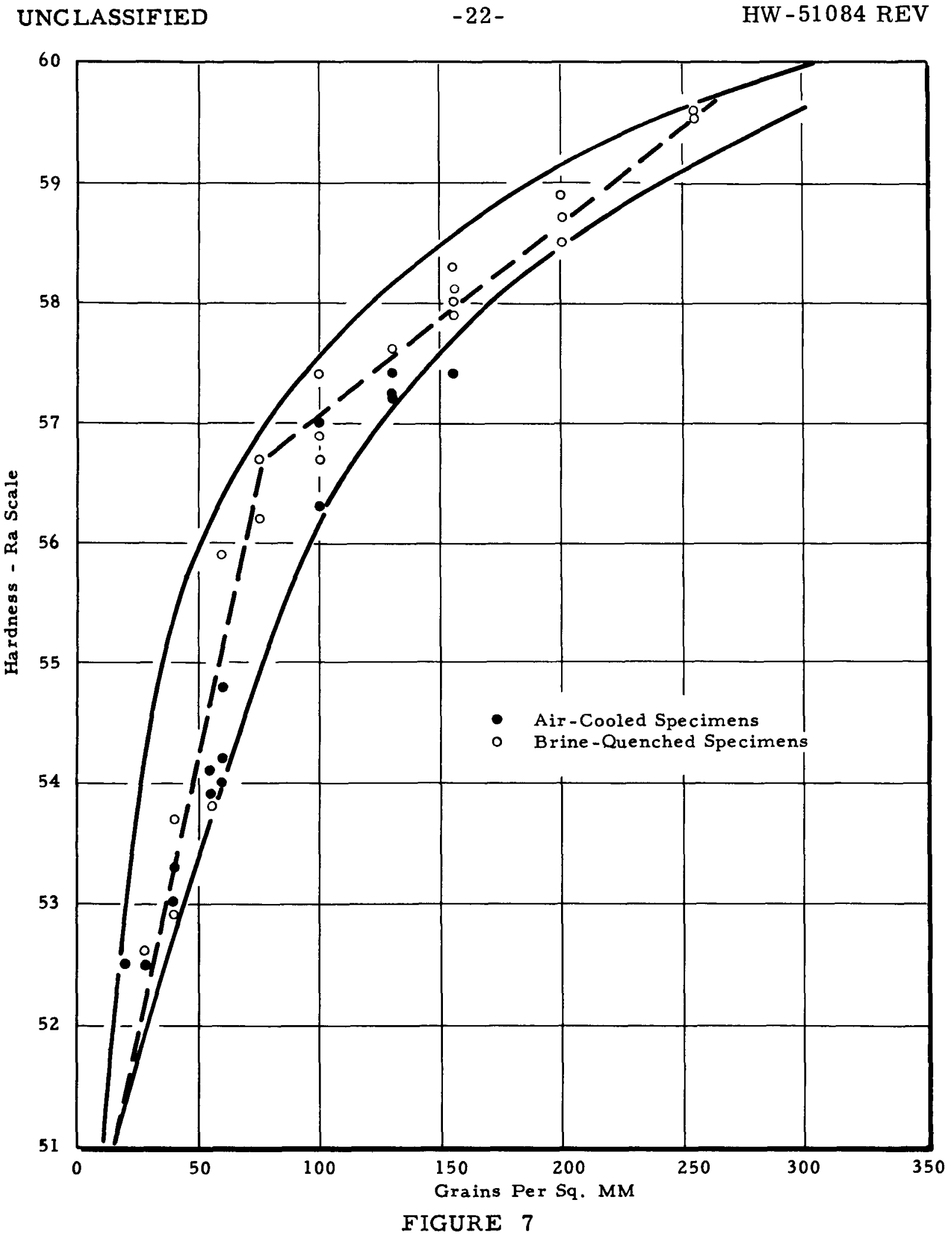

THE VARIATION OF HARDNESS WITH GRAIN SIZE 


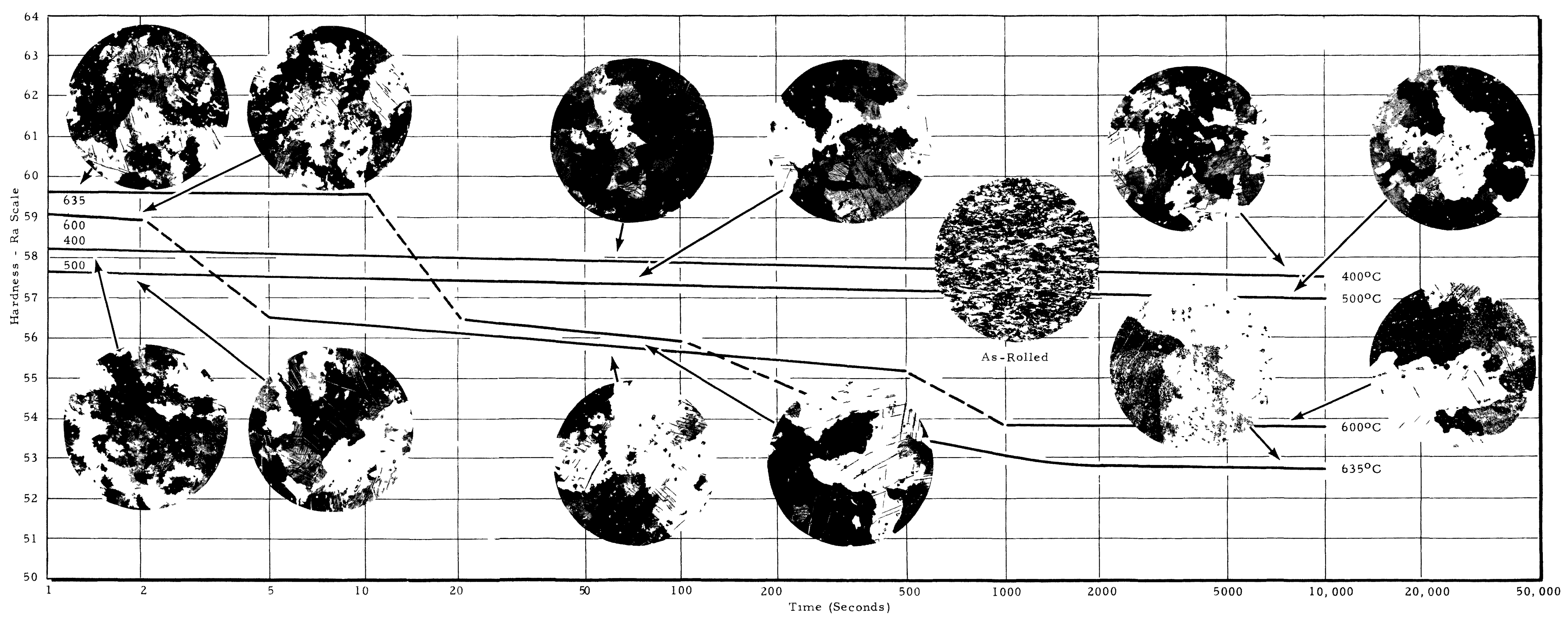




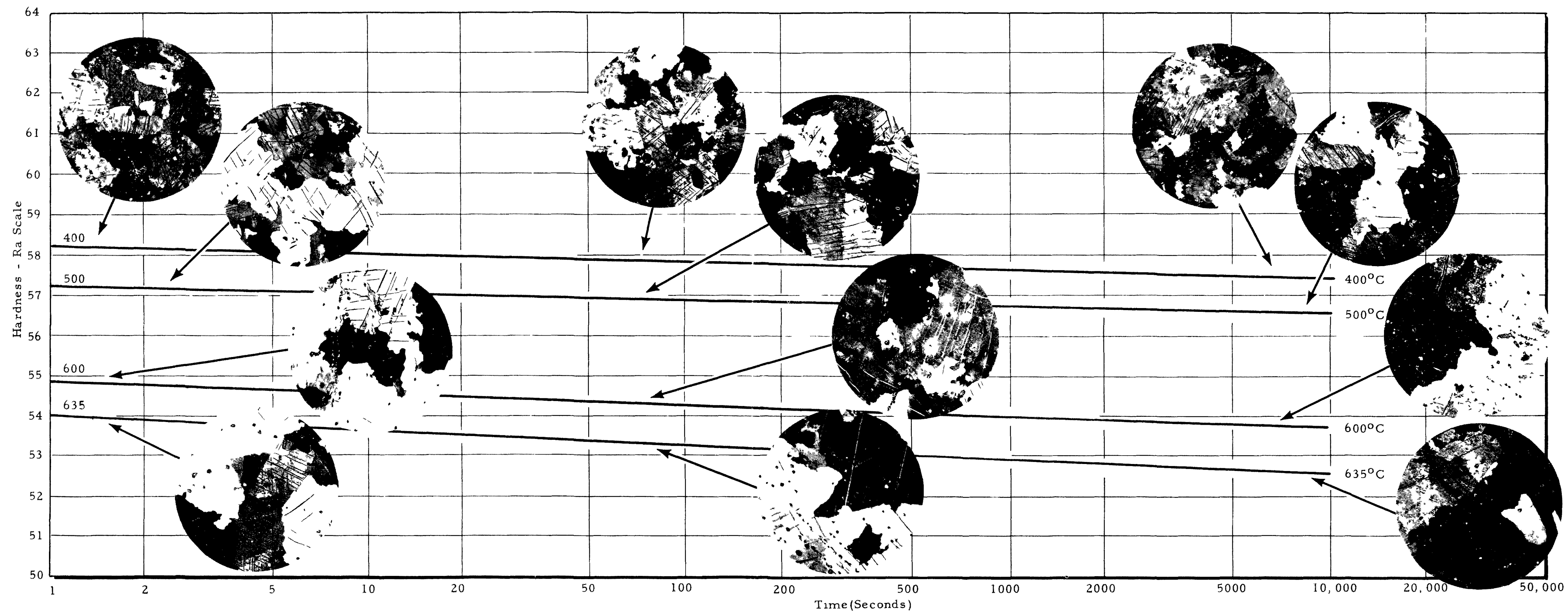



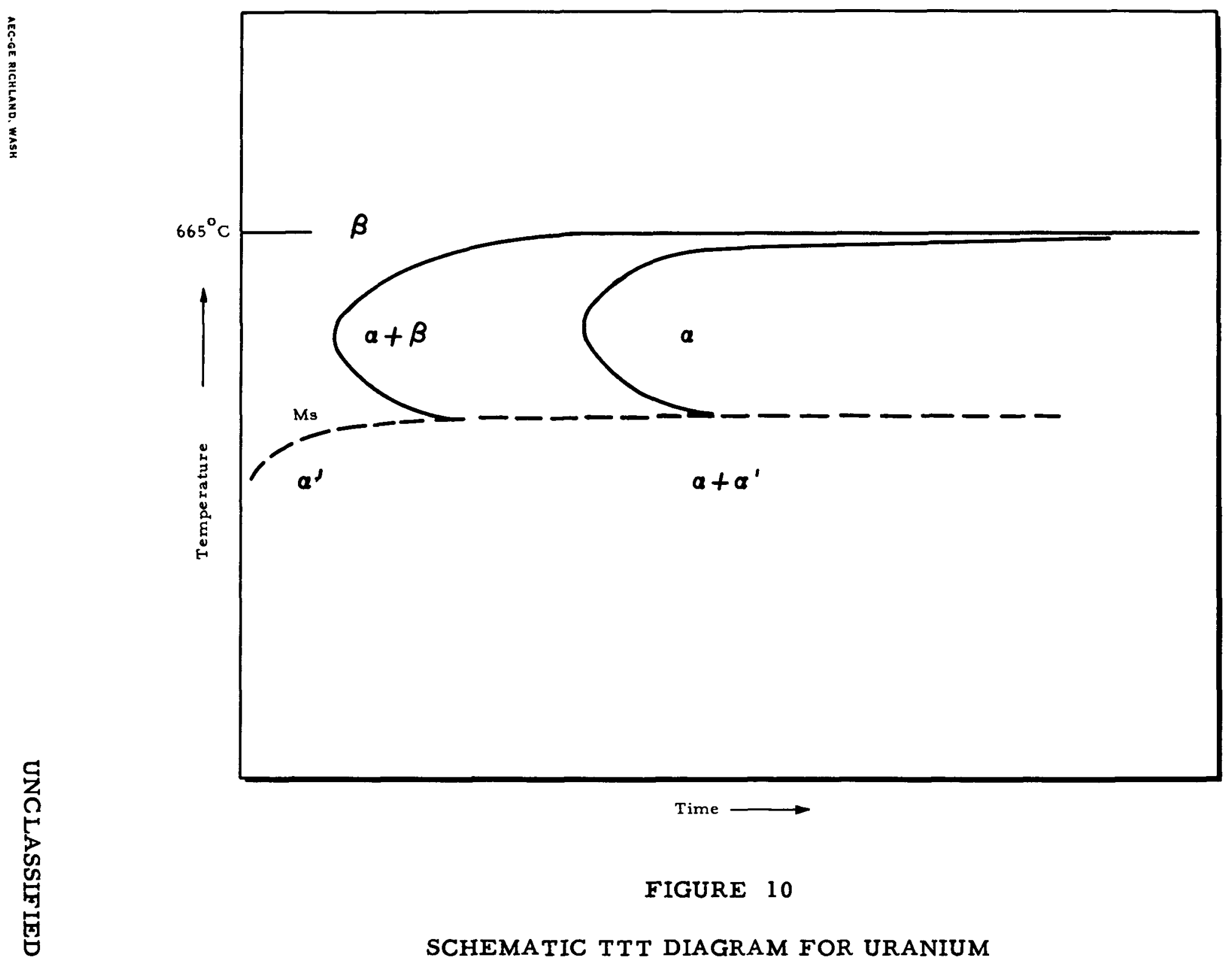

C 
APPENDIX

\section{CHEMICAL ANALYSIS OF INGOT URANIUM}

Chemical

Element

$\mathrm{C}$

$\mathrm{Cr}$

$\mathrm{Fe}$

$\mathrm{Mg}$

$\mathrm{Mn}$

$\mathrm{Si}$

$\mathrm{Ni}$

$\mathrm{Cl}$

$\mathrm{N}$

Density
Analysis (ppm)

275

12

70

4

10

40

50

$0-5$

60

$18.97 \mathrm{~g} / \mathrm{cm}^{3}$
Method of Determination

Gravimetric.

Spectrochemical, visual estimate from film.

Spectrochemical, densitometer.

Spectrochemical, visual estimate from film.

Spectrochemical, visual estimate from film.

Spectrochemical, densitometer.

Spectrochemical, visual estimate from film.

Gravimetric.

Gravimetric. 